\title{
Empirical Study on Intrinsic Motivation Factors of Employees in Transition Economies
}

\author{
Submitted 22/07/19, 1st revision 17/08/19, 2nd revision 24/09/10, accepted 25/10/19
}

\author{
Theranda Beqiri ${ }^{1}$
}

\begin{abstract}
:
Purpose: This research study aims to unequivocally discuss and explore the intrinsic motivation factors of the employees in transition economies. The purpose of this study is to find which are the main internal factors that motivate employees? Taking in to consideration changes to the economic systems, different factors derived from theories, as well as other research analyzed.

Design/Methodology/Approach: To describe the relationship between motivational factors that motivate workers today, we have developed a questionnaire which is distributed and filled by 510 respondents, not taking into account their hierarchy in the organization. Methodologies used in this research are Pearson correlation matrix to test the relationship with independent variables and dependent variable which in our case is intrinsic motivation and as a main econometric model binary logit is used

Findings: The research shows that most of the data that we have used in this model are correlated, and have high level of significance, and there is no multicollinearity. Whereas, in Binary Logit model used Cox \& Snell R Square is .696 meaning that our model is predicted by around 70 percent from the independent variables. From our research we found that most important intrinsic motivational factors are competence, job satisfaction, job recognition as well as financial rewards. There is no impact on intrinsic motivation that is dependent on finding the job interesting or not. Worthy of note is that the odds of employees to be intrinsically motivated are much higher in public institution than in private businesses.

Practical Implications: This study raises awareness of motivational factors in economies that are still in transition. Results of this study can serve as a good guide especially for small businesses and business startups on importance of behaviorist approach for motivation factors as competence and job recognition.

Originality/Value: this paper provides original insights of the compound relationship between different factors that have a direct affect in intrinsic motivation of employees' therefore as an outcome better job performance.
\end{abstract}

Keywords: Intrinsic motivation, employees, competence, job satisfaction, job recognition.

JEL Classification: $O 15$.

Paper Type: Research Paper

\footnotetext{
${ }^{1}$ University Haxhi Zeka, Faculty of Business, Email: Theranda.Beqiri@unhz.eu
} 


\section{Introduction}

In recent years we have been a witness of a lot of changes as in the political and economic specter as well as the way of doing businesses, as restructuring and privatization of the socially owned enterprises, there has also been changes in work structures and the traditional jobs security is not as in previous decades. Increase in competition has had its impact on difference of changes of the way that we are working these days. Since there are changes in the way that we are working these days there are also changes in motivational factors of employees especially in transition economies, like in Kosovo where this research has been conducted. Therefore there might had been changes in the way employees are motivated, as we might say that motivation is represented by forces acting on or within a person and forcing a person to behave in a certain, purpose-oriented way. Since, employees are very different from one another, their personal goals are also different, or saying it otherwise what they want to achieve from their work in the organization is diverse.

Human resource management is a basic organizational function that makes a significant contribution to the achievement of objectives not only in the field of business but also in other areas of human activity and achieving personal and organizational goals. The process of globalization as the most important process of recent decades and the free movement of capital and people as manpower has made enterprises more focused on handling and managing their employees well. Therefore, employee management is now considered a strategic and integrated approach that focuses on their employment, development and well-being, and within the enterprise are organized special units that only have the responsibility of managing its internal staff, and now the staff lies in the center attention and is considered as one of the company's main priorities (Robbins and DeCenzo, 2011).

Motivating workers is very important, as people play a key role and are the main source of an enterprise. Therefore each organization, regardless of its activity, must without a doubt motivate the workers to achieve its goals. Signs of a person's motivation are an energy and determination to achieve the goal. Management has an important role in providing motivational environment in the workplace in order to increase efficiency. Gagne and Deci (2005) found when they analyzed contributions of theory and research related to intrinsic motivation predictions and some identified regulatory styles on motivation factors, that they do have positive outcomes to employees and organization. While, Putra et. al. (2017) when testing crowding theory in employees in hospitality sector regarding motivation did not find that when introducing extrinsic motivation as financial rewards that intrinsic motivation reduces, but that they can both work together in motivating employees.

\section{Literature Review and Theories on Motivation}

Different Organizations and institutions offer different jobs and activities for their employees. Each institution should have appropriate structure and facilities that 
provide environment and conditions for them to feel motivated. Each employee has his own factors of motivation as we individually evaluate specific motivational elements and factors. Since employees are very different from one another, they have also different personal goals, hence what they want to achieve from their work in the organization is diverse. One of the more general definition on motivation at work we can say that it is related with the driving forces to perform well on the job and relevant tasks given by their supervisors. In the field of motivation there are numerous theoretical models that explain and treat motivated behavior in different work environments. There are two types of motivation identified by Herzberg, (1957): internal motivation - include responsibility as feel that work is important, autonomy as freedom to act, opportunity to use and develop skills and abilities, interesting and challenging work and opportunities for advancement. External motivation - Includes bonuses, such as high pay, praise, or elevation and punishment, such as disciplinary action, salary prohibition, or criticism.

External motivators can have an immediate and powerful effect, but this will not necessarily last too long. Internal motivators, who are linked to the quality of work, are likely to have a deeper and longer-term effect, because they are inherent to individuals and not imposed on them from abroad (Armstrong, 2006). Considering changes that have been in the way that the work, has been performed in recent years and motivation factors for workers have changed and are becoming more important therefore they have their influence in the management decisions.

According to Cameron and Green (2015) change from a behaviorist perspective if we relate to the McGregor's Theory X the only way to motivate people through changes are with combinations of reward and punishment, although we might have a right reward strategy and performance management it all depends on individuals behavior. Herzberg's ideas suggest that there is something more at play than reward and punishment when it comes to motivating people. Where we can say, that the provision of Herzberg's motivators can be used as some sort of reward for correct behavior. The cognitive approach to change of the workers motivation builds on the behaviorists approach by putting behavior into the context of beliefs, and focusing more decisively on results. Gagne and Deci (2005) go further with analyzing selfdetermination theory that explains the intrinsic and extrinsic motivation, saying that sometimes it is difficult to be applied in the work setting because of the simple dichotomy that contains.

By suggesting that extrinsic motivators as salaries and bonuses undermine the intrinsic motivation, although Deci et al. (1999) proved that this is not the case when there are no tangible rewards. Kuvaas et al. (2017) also found that there is a negative relationship between intrinsic and extrinsic motivation. Cognitive evaluation theory suggests that feelings of competence and autonomy are important for intrinsic motivation while deadlines, monitoring evaluation diminish the intrinsic motivation. People's engagements in the organizations are dependent on intrinsic motivation since they arise from the employee's feelings and they are bound up with the work 
itself. Extrinsic motivation is not inherent part of the work but they may come from the controlling side of the work as monitoring, promised compensation, praise or criticism on work done. When employees have intrinsic motivation it does not mean that they ignore the outcomes of the work (Amiable, 1996). Burton et al. (2006) suggest in their study that intrinsic motivation is related with self-regulation measures and inclusion of implicit in addition to explicit measures contributes to predictions of goal achievement and motivation theories developed by selfdetermination theory.

Self-determination theory is further developed and is more complete since it includes cognitive evaluation theory within. Therefore, when it comes to organizational behaviors it offers a better and more explanatory approach regarding intrinsic motivations which are founded in interest and extrinsic motivation which are founded in importance and are related to performance, satisfaction, trust, and wellbeing in the workplace (Gagne and Deci, 2005). Olafsen et al (2015) by testing selfdetermination theory found that although the money and motivation are related, when it comes to intrinsic motivating factors the interpersonal climate has the greater influence in motivation than variables that are related to compensations, the only important variable that they found that was important was procedural justice of pay. Oudeyer and Kaplan (2008) suggested that motivation factors can be seen as a driving force if we treat them as an overall issue, but if we study them on detail we can find that stimulating forces are divided in Intrinsic and extrinsic factors where the individuals that are able to promote this phenomenon, are the ones that manage to fulfill their own personal and the organizations goals.

Intrinsic motivation indicates the pleasure and satisfaction that derives from the work itself, extrinsic is more connected with benefits and rewards recognition and competition that arise from performing a work activity. Motivating an individual's work reflects not only the ability to increase productivity, but also an increase of efficiency of human resources management in terms of management of human capital in terms of promoting performance, personal adjustment and growth group or organizational level.

The literature review done by Kanfer et al (2017), found that when it comes to organizational goal achievement, the realization of the goals is possible when employees are aware of them. Along with having ownership of this goals and believing that they are achievable, taking into account that they also contain intrinsic and extrinsic outcomes for the employees. Another interesting issue is that motivation contains cognition and influence. Recent literature from Woolley and Fishbach (2018) found that immediate rewards increase employee motivation compared with delayed rewards, by increasing their activities on goal achievements. Whereas Kooij et al. (2011) found that motivation factors are diverse depending on age not only from the learning organizations, but also from that with a life span development theory. Although they found that there are relations of age with intrinsic motivations for all occupations, while the lifespan has some contextual and 
social implications in the result which are diverse also by the subgroups. Guillén et al. (2015) studied motivation from the ethical side by introducing also except intrinsic and extrinsic factors as psychological and material factors, also the moral and spiritual influence of the motivation. Keeping in mind that employees and also the managers are human and that during work they use except knowledge also their creativity, talent and sometimes spirituality.

Johnson and Nandy (2015) studied motivational factors from leadership side and found that there is a relationship between leadership and job satisfaction in regards to motivation, and the difference in leadership sides, skills and knowledge of the leaders are related to the impact they have in their followers and their motivation. Menges et al. (2017) go further with analyzing job performance when there is no intrinsic motivation in workplace they suggest that carrying and supporting for family is very important motivation factor when jobs are not interesting and monotonous, in reaching very good work related performance.

\section{Research Methodology, Data Collection and Empirical Results}

\subsection{Research Methodology and Data Collection}

The research strategy is directly dependent on the way the research questions are developed. Empirical studies are intended to provide causal explanations respectively the relationship of variables among themselves. Since this research is focused on the cause-effect phenomenon (Collis and Hussey, 2003), namely to see what are the main factors and causes that have impact on intrinsic motivation. Data used in this paper are based on the independent research survey conducted by author in whole regions of Kosovo during the year 2018, the sample was randomly selected from the public and private businesses.

The methodology used is through interviews, $46.1 \%$ of questionnaires were filled in Public Institutions and $53.9 \%$ in Private Businesses. The questionnaire also considers the general variables such as age, education, type of institution that they work public or private sector. In the first part of the research, we have used some of the simpler and easier processed methods, whenever possible and more descriptive in nature. For testing the explanatory hypothesis regarding factors that have impact on intrinsic and extrinsic in motivation of employees from the research studies and theories mainly cognitive evaluation theory and self-determination theory that has been studied, we have developed some research questions relevant to this issue.

To describe the relationship between motivation and motivational factors that motivate workers today, we have developed a questioner to test the hypothesis on correlation of the different factors as research questions; job satisfaction, level of education, competence, recognition for work, stimulation pay and so on which is distributed and filled by 510 respondents not taking into account their hierarchy in the organization. So, the interviews were conducted with, employees, managers, 
middle managers, taking into account that they are all employees in one stage or another. Statistical techniques were used to analyze and process econometric research and for testing the relevant hypothesis. The Pearson correlation method is used to ascertain how and to what extent the two variables are linearly linked to one another and how they affect intrinsic motivation. The qualitative method is used, with using the Binary Logit Model. The null Hypothesis is:

HO a=O Intrinsic Motivation of employees is dependent on cognitive and selfdetermination factors.

From the main null hypothesis we have derived also other hypothesis that will help in testing the main Hypothesis on which factors have the highest impact on intrinsic motivation of employees.

H1: Interesting Job has a significant and positive Impact on Intrinsic motivation of employees;

H2: Financial rewards has a significant and positive Impact on Intrinsic motivation; H3: Job satisfaction and job recognition has a significant and positive Impact on Intrinsic motivation;

H4: The intrinsic motivation is dependent on Age and Education level of employees;

H5: Giving competence to the employees has a positive impact and increases intrinsic motivation.

\subsection{Empirical Results of Correlation Matrix and Binary Logistic Model}

\subsubsection{Empirical Results of Correlation Matrix}

First we will verify that the variables that we have used in this model are correlated, we will test their significance and we checked for multicollinearity between the independent variables and dependent variable which in our case is intrinsic motivation. From the results of the Pearson Correlation regarding intrinsic motivation factors there is no relationship between interesting job and motivation. But as we can see from the table 1 below intrinsic motivation is positively correlated, Pearson Correlation $0.161 * *$ which is significant .000 at the 0.01 level (2-tailed) with stimulation pay, while intrinsic motivation is negatively correlated with the level of education -.148** which is significant .000 at the 0.01 level (2tailed), where we can interpret that with the more investment in human capital and higher educated employees extrinsic motivators are more important than intrinsic motivators.

Job satisfaction is positively correlated with intrinsic motivation with Pearson Correlation $.211^{* *}$ which is significant .000 , while we didn't find any relationship with age of the employees and intrinsic motivation, the level of management similar like more educated workers have negative correlation factor $-.101 *$ with intrinsic motivation therefore we can say that with the increasing levels of management the extrinsic motivations are more important than intrinsic motivations for employees 
which is significant .022 at the 0.01 level (2-tailed). When it comes to variables recognition for work and variable competence of the employees we see that they are highly correlated with intrinsic motivation of workers at the 0.01 level, with $.904^{* *}$ for work recognition and $.933^{* *}$ for competence that is given to the employees with high significance level of .000 (2-tailed).

Table 1. Pearson Correlation Matrix

\begin{tabular}{|c|c|c|c|c|c|c|c|c|c|c|c|}
\hline \multirow{2}{*}{$\begin{array}{l}\text { Intrinsic } \\
\text { Motivator }\end{array}$} & $\begin{array}{l}\text { Pearson } \\
\text { Correlation }\end{array}$ & 1 & & & & & & & & & \\
\hline & Sig. (2-tailed) & & & & & & & & & & \\
\hline \multirow{2}{*}{$\begin{array}{l}\text { Interesting } \\
\text { job }\end{array}$} & $\begin{array}{l}\text { Pearson } \\
\text { Correlation }\end{array}$ & .066 & 1 & & & & & & & & \\
\hline & Sig. (2-tailed) & .135 & & & & & & & & & \\
\hline \multirow{2}{*}{$\begin{array}{l}\text { Stimulatio } \\
\text { n pay }\end{array}$} & $\begin{array}{l}\text { Pearson } \\
\text { Correlation }\end{array}$ & $.161^{* *}$ & .039 & 1 & & & & & & & \\
\hline & Sig. (2-tailed) & .000 & .374 & & & & & & & & \\
\hline \multirow{2}{*}{$\begin{array}{l}\text { level of } \\
\text { education }\end{array}$} & $\begin{array}{l}\text { Pearson } \\
\text { Correlation } \\
\end{array}$ & $-.148^{* *}$ & .007 & -.047 & 1 & & & & & & \\
\hline & Sig. (2-tailed) & .001 & .873 & .287 & & & & & & & \\
\hline \multirow{2}{*}{$\begin{array}{l}\text { Job } \\
\text { Satisfactio } \\
\mathrm{n}\end{array}$} & $\begin{array}{l}\text { Pearson } \\
\text { Correlation } \\
\end{array}$ & $.211^{* *}$ & $.196^{* *}$ & .040 & $-.179^{* *}$ & 1 & & & & & \\
\hline & Sig. (2-tailed) & .000 & .000 & .362 & .000 & & & & & & \\
\hline \multirow{2}{*}{ Age } & $\begin{array}{l}\text { Pearson } \\
\text { Correlation }\end{array}$ & .065 & .025 & .022 & -.079 & .021 & 1 & & & & \\
\hline & Sig. (2-tailed) & .145 & .574 & .627 & .075 & .631 & & & & & \\
\hline \multirow{2}{*}{$\begin{array}{l}\text { Level of } \\
\text { Manageme } \\
\text { nt }\end{array}$} & $\begin{array}{l}\text { Pearson } \\
\text { Correlation }\end{array}$ & $-.101^{*}$ & $-.095^{*}$ & -.011 & $.289^{* *}$ & -.031 & .059 & 1 & & & \\
\hline & Sig. (2-tailed) & .022 & .033 & .809 & .000 & .488 & .184 & & & & \\
\hline \multirow{2}{*}{$\begin{array}{l}\text { Recognitio } \\
\mathrm{n} \text { for Work }\end{array}$} & $\begin{array}{l}\text { Pearson } \\
\text { Correlation }\end{array}$ & $.904^{* *}$ & .038 & .079 & $-.142^{* *}$ & $.173^{* *}$ & .045 & $-.110^{*}$ & 1 & & \\
\hline & Sig. (2-tailed) & .000 & .393 & .075 & .001 & .000 & .315 & .013 & & & \\
\hline \multirow{2}{*}{$\begin{array}{l}\text { Competen } \\
\text { ce }\end{array}$} & $\begin{array}{l}\text { Pearson } \\
\text { Correlation }\end{array}$ & $.933^{* *}$ & $.089^{*}$ & $.113^{*}$ & $-.137^{* *}$ & $.190^{* *}$ & .045 & $-.124^{* *}$ & $.878^{* *}$ & 1 & \\
\hline & Sig. (2-tailed) & .000 & .044 & .011 & .002 & .000 & .308 & .005 & .000 & & \\
\hline \multirow{3}{*}{ Institution } & $\begin{array}{l}\text { Pearson } \\
\text { Correlation }\end{array}$ & -.018 & -.007 & .036 & $-.096^{*}$ & .016 & -.066 & $.112^{*}$ & -.029 & -.072 & 1 \\
\hline & Sig. (2-tailed) & .690 & .882 & .423 & .030 & .717 & .137 & .011 & .517 & .105 & \\
\hline & $\mathrm{N}$ & 510 & 510 & 510 & 510 & 510 & 510 & 510 & 510 & 510 & 510 \\
\hline \multicolumn{12}{|c|}{$\begin{array}{l}\text { Note: } * * \text { Correlation is significant at the } 0.01 \text { level (2-tailed). *. Correlation is significant at the } 0.05 \text { level (2- } \\
\text { tailed). }\end{array}$} \\
\hline
\end{tabular}

\subsubsection{Empirical Results of Binary Logit Model}

Binary Logit model is used to explain the important factors and their relationship with intrinsic motivation in order to test the hypothesis, interviews and responses in the research. For convenience we define the response to be $\mathrm{Y}=0$ or 1 , with $\mathrm{Y}=1$ denoting the occurrence of the event of interest. Which in our research is what the main factors that motivate employees are. Therefore, it is aimed to introduce application processes of binary logistic regression analysis using real independent research data. Given that according to Cokluk (2010), it is important to study with higher number of observations which in our case are 510, because in estimations by low numbers of observations, reliability of the model decreases. When we have a 
proportion as a response, we use a logistic or logit transformation to link the dependent variable to the set of explanatory variables. The logit formulae has the form: $\operatorname{Logit}(\mathrm{P})=\log [\mathrm{P} /(1-\mathrm{P})]$.

The term within the square brackets is the odds of an event occurring Hinton et al (2014). The model was assessed with $\mathrm{p}$ value of chi-square statistics, Model ChiSquare statistic determines if the overall model is statistically significant, which have the value of $\mathrm{p}=.000<0.005$ Here the chi-square is highly significant (chisquare $=606.783 \mathrm{df}=8, \mathrm{p}<.000$ ) so our model fits the data. The Omnibus Tests in table 2, of Model Coefficients is used to check that the model, significant value means that there is a current correlation between the combination of predicted variables and the predictive variables. The -2LL value for this model $67.755 \mathrm{a}$ tells us that the data are significant and fit the null model. Logistic models are typically interpreted in terms of odds ratios, for continuous predictors, a one-unit increase in a predictor value indicates the change in odds expressed by the displayed odds ratio. Nagelkerke R Square is .948 while Cox \& Snell R Square is .696. Meaning that our model is predicted by around 70 percent from the independent variables.

Table 2. Omnibus Tests of Model Coefficients \& Model Summary

\begin{tabular}{|c|c|c|c|}
\hline & Chi-square & $\mathrm{df}$ & Sig. \\
\hline Model & 606.783 & 8 & .000 \\
\hline \multicolumn{4}{|c|}{ Model Summary } \\
\hline Step & \begin{tabular}{|ll}
-2 & Log \\
likelihood & \\
\end{tabular} & Cox \& Snell R Square & $\begin{array}{l}\text { Nagelkerke } \\
\text { Square }\end{array}$ \\
\hline 1 & $67.755^{\mathrm{a}}$ & .696 & .948 \\
\hline
\end{tabular}

Source: Developed by the author.

The Variables in the Equation output shows us that the regression equation is:

$\log (p / 1-p)=b 0+b 1 * x 1+b 2 * x 2+b 3 * x 3+b 3 * x 3+b 4 * x 4+b 5 * x 5+b 6 * x 6$

Independent variables are: $\mathrm{X} 1=\mathrm{G}$ Interesting job, $\mathrm{X} 2=$ Stimulation pay, $\mathrm{X} 3=$ Level of education, X4 = Job Satisfaction, X5 = Recognition for Work X6= Competence, $\mathrm{X} 7=$ Institution, $\mathrm{X} 8=$ Age while the dependent variable is Intrinsic Motivation. These are the values for the logistic regression equation for predicting the dependent variable from the independent variable. They are in log-odds units.

Ln (odds) $=-26.156-$

$.977 \mathrm{IJob}+2.518 \mathrm{SP}+2.518 \mathrm{LE}+.2 .364 \mathrm{JS}+4.937 \mathrm{RW}+6.324 \mathrm{Comp}+1.125 \mathrm{Inst}+.763 \mathrm{Age}$ 
Table 3. Variables in the Equation-Binary Logit

\begin{tabular}{|l|l|l|l|l|l|l|}
\hline & B & S.E. & Wald & df & Sig. & Exp(B) \\
\hline Interesting job & -.977 & .842 & 1.346 & 1 & .246 & .377 \\
Stimulation pay & 2.518 & .857 & 8.633 & 1 & .003 & 12.403 \\
Level of education & .373 & .440 & .717 & 1 & .397 & 1.452 \\
Job Satisfaction & 2.364 & .903 & 6.852 & 1 & .009 & 10.636 \\
Recognition for & 4.937 & .892 & 30.641 & 1 & .000 & 13.929 \\
Work & 6.324 & 1.020 & 38.466 & 1 & .000 & 55.793 \\
Competence & 1.125 & .558 & 4.062 & 1 & .044 & 3.080 \\
Institution & .763 & .499 & 2.335 & 1 & .126 & 2.144 \\
Age & -26.156 & 4.760 & 30.196 & 1 & .000 & .000 \\
Constant &
\end{tabular}

Source: Developed by the author.

According to Harrell (2015) Wald statistic, tests the unique contribution of each predictor, in the context of the other predictors by holding constant the other predictors in other words they exclude any overlap between the predictors, in our case most of the predictors meets the $p<0.5$ conventional criteria of significance. We can see from the table 3 Wald statistic tests that this criterion is full filled since, predictive variables are not the same. Wald statistic for stimulation pay is 8.633 , for level of education Wald statistic is .717 ,for job satisfaction is 6.852 , for recognition for work is 30.641 , for variable competence is 38.466 and for variable institution is 4.062 therefore there is no overlapping over the predictors in the model.

The Variables in the Equation output also gives us exponential function of the regression Exp (B). This is better known as the odds ratio predicted by the model. This odds ratio can be computed by raising the base of the natural log to the bth power, where $b$ is the slope from our logistic regression equation. The $\operatorname{Exp}(\mathrm{B})$ column Odds Ratio tells us that employees do not find interesting job as the motivation factor since it is not significant, therefore we can say that we reject $\mathrm{H} 1$ : Interesting Job has a significant and positive Impact on Intrinsic motivation of employees.

While we can say that stimulation pay increases the odds of motivation for employees which if employees are financially rewarded the odds of increased motivation is approximately 12 times higher if there is a stimulation pay ,therefore we can say that we accept the second Hypothesis H2: Financial rewards has a significant and positive Impact on Intrinsic motivation, which is in contradiction 
with Deci et al. (1999), Kuvaas et al, (2017) findings that extrinsic motivation as financial reward diminishes intrinsic motivation.

The model predicts that the odds of employees that are satisfied with their job are approximately 10 times more intrinsically motivated than those that are not, keeping everything else equal. The workers which receive recognition for work well done increases the intrinsic motivation for approximately 14 times compared with the ones that do not have recognition for their work which gives us a strong significance level to accept the third hypothesis H3: Job satisfaction and job recognition has a significant and positive Impact on Intrinsic motivation.

Although, the level of education and age does not have any impact on the level of motivation in our research therefore we reject the forth hypothesis $\mathrm{H} 4$ : The intrinsic motivation is dependent on Age and Education level of employees. The most important factor according to our model is the trust of the institution to the employees by giving them competence and trust of the supervisors to the workers that they are skilled, and have knowledge to work without monitoring and they increases the intrinsic motivation by 55 times keeping everything else equal. Hence we have a very significant results to accept the hypothesis H5: Giving competence to the employees has a positive impact and increases intrinsic motivation. Depending on Institution where they work also the level of motivation differs we find that the odds of employees that work in in public institutions are 3 times higher to be intrinsically motivated than those in private sector.

Although factors like age, education level and interesting job are not significant. Job satisfaction, competence, job recognition and financial rewards are highly significant and the odds of motivating employees are high we can say that the null hypothesis is tested and accepted H0: $\overline{\mathrm{a}}=0$ Intrinsic Motivation of employees is dependent on cognitive and self-determination factors.

\section{Conclusion and Discussion}

People in the enterprise are considered the most valuable capital and the motivation of the employees is the main focus of the managers. Motivation of workers is of great importance for the future of the enterprise and achievement of its goals. Motivated workers make more efforts and utilize their skills to achieve the goals of the enterprise that positively contributes to increased performance. Employee dissatisfaction is caused as a result of low level of motivation by managers. It is incumbent on any manager to ensure that employees have a high degree of motivation. Understanding the needs, desires and goals of the workers and trying to fulfill them leads to achieving high results and achieving the goals of the enterprise. Employee motivation has a positive impact on achieving the quality of products and services, increasing efficiency and successful productivity is the motivation of employees. 
From the Pearson correlation matrix we found that the higher level of education, as well as higher levels of management are negatively correlated with intrinsic motivation, this might come due to higher levels of human capital investments at these employees and it seems that they are more motivated by the extrinsic motivation higher salaries, and so on .Although In our research we also found that Financial rewards has a significant and positive Impact on Intrinsic motivation, which is in line with Putra et. al. (2017) findings and in contradiction with Deci et al. (1999) and Kuvaas et al, (2017) findings that extrinsic motivation as financial reward diminishes intrinsic motivation.

We did not find that if the job is interesting or not has its impact on intrinsic motivation, and from our research we didn't find that employees age is an important factor on intrinsic motivation as did Kooij et al. (2011) considering that they found that depending on age also motivation factors are diverse Organizations should be well aware of employee expectations and take steps to meet these expectations.

Therefore each organization, regardless of its activity, must without a doubt motivate the workers to achieve its goals. Signs of a person's motivation are an energy and determination to achieve the goal. As well as to set goals, that are achievable, for this issue they can use Human resource managers to make a significant contribution to the achievement of objectives not only in the field of business but also in other areas of human activity and achieving personal and organizational goals. This can be achieved through the use of different models of their reward and if the private businesses do not have the possibility to introduce rewards to have more initiatives for introducing a climate in the organization where there is more competence given to the employees, also a climate that the employees that have better performance are recognized for the work done and goals achieved. From our research we found that employee in public institutions have three times higher odds of being intrinsically motivated than in private businesses, this might be due to Kosovo being in the early stages of transition and the legislation on labor law is in the first stages of implementation.

As a conclusion, we have come to understand that the success of enterprises without the motivation of workers is impossible Fulfilling the needs and interests of employees leads to achieving enterprise goals and increasing efforts to show a high performance. The success of the enterprise depends on how satisfied the workers are at work.

The limitation of the study is that there is not any other study that have done the research on motivation of employees at work, with the emphasize on intrinsic motivation, specifically in transition economies, taking in to consideration that are changes in economic systems. Further research can be done to include other countries in the research and analyze different stages of transition. 


\section{References:}

Amabile, T.M. 1997. Motivating creativity in organizations: On doing what you love and loving what you do. California management review, 40(1), 39-58.

Armstrong, M. 2006. A handbook of human resource management practice. Kogan Page Publishers

Burton, K.D., Lydon, J.E., D'alessandro, D.U. \& Koestner, R. 2006. The differential effects of intrinsic and identified motivation on well-being and performance: prospective, experimental, and implicit approaches to self-determination theory. Journal of personality and social psychology, 91(4), 750.

Cameron, E. \& Green, M. 2015. Making sense of change management: A complete guide to the models, tools and techniques of organizational change. Kogan Page Publishers.

Cokluk, O. 2010. Logistic Regression: Concept and Application. Educational Sciences: Theory and Practice, 10(3), 1397-1407. Collis, J. and Hussey, R."Business Research: A Practical Guide to Undergraduate and Postgraduate Students (2nd Ed.)", 2003, Palgrave Macmillan.

De Cenzo, D.A., Coulter, M. \& Robbins, S. P. 2011. Fundamentals of management. Pearson Higher Ed.

Deci, E.L., Koestner, R. \& Ryan, R.M. 1999. A meta-analytic review of experiments examining the effects of extrinsic rewards on intrinsic motivation. Psychological bulletin, 125(6), 627 .

Gagné, M. \& Deci, E.L. 2005. Self-determination theory and work motivation. Journal of Organizational behavior, 26(4), 331-362.

Guillén, M., Ferrero, I. \& Hoffman, W.M. 2015. The neglected ethical and spiritual motivations in the workplace. Journal of business ethics, 128(4), 803-816.

Harrell, Jr.F.E. 2015. Regression modeling strategies: with applications to linear models, logistic and ordinal regression, and survival analysis. Springer.

Herzberg, F., Mausnes, B., Peterson, R.O., \& Capwell, D. F. 1957. Job attitudes; review of research and opinion.

Johnson, S. M., \& Nandy, S. 2015. Leadership skills, job satisfaction, and motivation in the workplace: a phenomenological research study. Journal of Perspectives in Organizational Behavior, Management, \& Leadership, 1(1), 10-14.

Kanfer, R., Frese, M., \& Johnson, R. E. 2017. Motivation related to work: A century of progress. Journal of Applied Psychology, 102(3), 338.

Kooij, D. T., De Lange, A. H., Jansen, P. G., Kanfer, R., \& Dikkers, J. S. 2011. Age and work-related motives: Results of a meta-analysis. Journal of Organizational Behavior, 32(2), 197-225.

Kuvaas, B., Buch, R., Weibel, A., Dysvik, A., \& Nerstad, C. G. 2017. Do intrinsic and extrinsic motivation relate differently to employee outcomes?. Journal of Economic Psychology, 61, 244-258.

Menges, J. I., Tussing, D. V., Wihler, A., \& Grant, A. M. 2017. When Job Performance is All Relative: How Family Motivation Energizes Effort and Compensates for Intrinsic Motivation. Academy of Management Journal, 60 (2), 695-719. http://dx.doi.org/ 10.5465/amj.2014.0898

Olafsen, A. H., Halvari, H., Forest, J., \& Deci, E. L. 2015. Show them the money? The role of pay, managerial need support, and justice in a self-determination theory model of intrinsic work $\mathrm{m}$

Oudeyer, P. Y., \& Kaplan, F. 2008. How can we define intrinsic motivation. In Proc. of the 8th Conf. on Epigenetic Robotics (Vol. 5, pp. 29-31). 
Putra, E. D., Cho, S., \& Liu, J. 2017. Extrinsic and intrinsic motivation on work engagement in the hospitality industry: Test of motivation crowding theory. Tourism and Hospitality Research, 17(2), 228-241. Motivation. Scandinavian journal of psychology, 56(4), 447-457.

Woolley, K., \& Fishbach, A. 2018. It's about time: Earlier rewards increase intrinsic motivation. Journal of personality and social psychology, 114(6), 8. 